\title{
Eager to Leave? Intentions to Migrate Abroad among Young People in Kyrgyzstan
}

\author{
Victor Agadjanian \\ Arizona State University \\ Lesia Nedoluzhko \\ Max Planck Institute for Demographic Research \\ Gennady Kumskov \\ Kyrgyz-Russian Slavic University
}

\begin{abstract}
This study examines young people's intentions to migrate abroad in Kyrgyzstan, focusing in particular on differences between Asian and European-origin ethnic groups. The multivariate analyses of recent survey data show that even after controlling for socioeconomic characteristics and social embeddedness Europeans are significantly more inclined to migrate than Asians. Whereas no gender differences in migration intentions among either group are detected, marriage, childbearing, and social capital exhibit distinct ethnic-specific effects. Although economic considerations are prevailing stimuli for migration in both groups, the results point to the formation of two dominant ethnic-specific migration preference types for temporary migration among Asians and permanent migration among Europeans.
\end{abstract}

\section{INTRODUCTION}

The population movements that accompanied and followed the dissolution of the Soviet Union in 1991 have attracted considerable attention in the literature (e.g., Azrael et al., 1996; Subbotina, 1997; Iontsev, 1998; Kulu and Tammaru, 2000; Korobkov and Zaionchkovskaia, 2004; Tishkov, Zayonchkovskaya, and Vitkovskaya, 2005). Indeed, international migration has been a defining demographic, socioeconomic, and political phenomenon in the part of the world that once constituted a single country and now is composed of several

${ }^{1}$ This project was supported by a research grant from the National Council for Eurasian and East European Research (NCEEER). The authors are also grateful to the staff of the Surveys Department of the National Statistical Committee of the Kyrgyz Republic for their assistance with data collection. 
sovereign nations. As was largely the case of migration in the immediate aftermath of the breakdown of the Soviet empire, most current migration flows involve the Russian Federation as the main recipient of migrants and the former Soviet republics of Central Asia and the Caucasus as their main donors (Laruelle, 2006; Mansoor and Quillin, 2006). While there is considerable continuity in factors that shape these migration flows, new forces, reflecting new political and economic realities of post-Soviet Eurasia, have also emerged. This study addresses continuity and change in the region's international migration dynamics by examining intentions to migrate abroad among young people in the Central Asian nation of Kyrgyzstan. Because the collapse of the Soviet Union brought to the fore and rearranged ethnic identities and because ethnicity has been a major factor in post-Soviet migration, we focus in particular on ethnic differences in migration intentions. We also look into other factors that might influence these intentions, such as gender, marriage and childbearing, social capital, and perceptions of economic and sociopolitical environment, as well as into ethnic differences in the role of these factors.

Migration links between Russia and Central Asia date back to pre-Soviet times. Thus, most of Central Asia was colonized by Tsarist Russia in the 19th century, and by the turn of the last century the region already saw a steady stream of settlers from Russia and other European parts of the Empire. The 1917 Bolshevik revolution and the subsequent incorporation of Central Asia into the USSR gave a new impetus to that migration flow. That flow turned into a massive influx during World War II, when a million and a half Volga Germans, seen by the Soviet government as a potential fifth column, were collectively banished to Kazakhstan and other republics of Central Asia and when the large-scale evacuation of the civilian population from the war-torn European parts of the country also took place. In the end and the aftermath of WWII, a number of other ethnic groups joined Volga Germans in Central Asia as "punished" peoples. Finally, a more benign, even if not fully voluntary, upswing of migration into the region resulted from the Soviet administration's efforts to develop modern agricultural production and to boost industrial modernization in Central Asia beginning in the 1950s. Since that period up until the final years of the Soviet Union, the region saw an intensive migration turnover with Russia and other European republics. This turnover, however, was composed mainly of ethnic Russians and other people of European origin (hereafter also referred to summarily as Europeans), some of whom were coming to Central Asia while others were leaving it (Lewis, 1971; Ball and Demko, 1978; Anderson and Silver, 1989; Tishkov, 1994). In contrast, despite the Soviet government's attempts to stimulate labor migration of Central Asian 
indigenous populations into the parts of the USSR experiencing growing labor shortages, mobility of the indigenous groups outside of Central Asia remained quite modest (Chernova, 1977; Rowland, 1988). Important changes in these flows started to happen in the 1970s and 1980s, well before the end of the Soviet Union, when in all Central Asian Republics, with the exception of Kazakhstan, out-migrants began to outnumber in-migrants (Rowland, 1990). The post-Soviet "exodus" from Central Asia was largely due to the continuation of that trend, as in-migration from the European successors of the Soviet Union into the region practically stopped (Zayonchkovskaya, 2000). Not surprisingly, massive emigration in the wake of the Soviet Union's collapse was composed mainly of Europeans and directed primarily toward the Russian Federation (Tishkov, 1997). Largely as a result of this ethnic-specific migration, the share of Europeans has declined considerably in all Central Asian states (Heleniak, 1997; Rowland, 2001). Although the levels of migration from Central Asia subsided after the initial post-Soviet surge, they have remained high in most Central Asian countries, including the country on which our study is focused - the Kyrgyz Republic, or Kyrgyzstan.

As some other former Soviet Republics, Kyrgyzstan, since its independence in 1991, has lived through a generalized societal crisis, painful economic reforms, and spells of political instability (Huskey, 1997; Cokgezen, 2004; Khamidov, 2006; Radnitz, 2006a). Today, the Kyrgyz Republic, with a population of just over five million people, remains one of the poorer postSoviet states, with the gross national income (GNI) per capita of just $\$ 490$ (World Bank, 2007). Kyrgyzstan is a multiethnic country: in addition to the Kyrgyz, the titular ethnic group that constitutes about 65 percent of the population, it has a sizeable minority of ethnic Uzbeks and other smaller groups autochthonous to Central Asia that inhabit mainly the country's south (hereafter we will refer to all Central Asian native groups as Asians). Kyrgyzstan is also home to a considerable number of ethnic Russians and other Europeans, who are largely concentrated in the northern part of the country, including the capital, Bishkek.

Like other Central Asian states, Kyrgyzstan has experienced large-scale net out-migration after the breakup of the Soviet Union. Most attention has been focused on early post-Soviet emigration of Europeans (Kumskov et al., 1997; Kumskov, 2002), but more recent survey data from Kyrgyzstan show that migration decisions are increasingly dominated by economic considerations and that both internal and international migration involves not only Europeans but also an increasing number of ethnic Kyrgyz and other Asians (Abazov, 1999; Kumskov, 2002; Shuller and Kudabayev, 2004). The economic 
attractiveness of Russia, which largely due to the soaring international fuel prices, has seen a virtually uninterrupted macroeconomic growth since the financial meltdown of 1998, is unquestionable, and so is, increasingly, that of neighboring Kazakhstan, which has also capitalized on the rising global demand for oil and natural gas (Economist, 2007a). Thus, Russia's GNI per capita in 2006 was $\$ 5,780$, i.e., almost twelve times that of Kyrgyzstan (World Bank, 2007), and incomes are much higher in large cities, especially Moscow, which are the strongest magnets for migrants. Kazakhstan's GNI per capita, $\$ 3,790$ (World Bank, 2007), is more modest than Russia's, but the difference may be counterbalanced by that country's geographic proximity to Kyrgyzstan, cultural similarities (the Kazakh language is similar to Kyrgyz, and in both countries Russian is widely spoken), and a less hostile official and public reception of migrants.

\section{NATURE AND DETERMINANTS OF MIGRATION INTENTIONS}

In a rapidly changing world, where mobility is made increasingly easier by expanding material, transportation, and informational resources, the motivations and expectations behind migration decisions and the very nature of these decisions grow more diverse. The literature often distinguishes between motivations that propel permanent (long-term) migration and those that drive temporary (short-term) moves (e.g., Goldstein, Goldstein, and Gu, 1993; Goldstein and Goldstein, 1996; Guilmoto, 1998; De Jong, 2000). This distinction, however, should not obfuscate the fact that migration intended as temporary often morphs into permanent and, vice versa, the intended permanent/long-term relocations sometimes are cut short due to a variety of intervening factors both at the sending and receiving ends of the migration process. The complexity of migration preferences and decisions includes other dimensions as well. For example, individuals can have different degrees of certainty regarding their future and the role of migration in that future. Some may have concrete and definite plans to migrate, while others may only entertain the possibility of migration or wish to migrate without making specific plans. Finally, another dimension of migration preferences and decisions is that defined by the number and characteristics of people who are to form a migrant unit. In that dimension, migration by individuals is typically contrasted with migration that involves family members (Boyd, 1989; Root and De Jong, 1991; Yang, 2000). Accordingly, intentions to migrate alone and intentions to migrate with spouses, children, parents and/or other family members can be compared and contrasted. In this study, we are able to 
distinguish between these different types and levels of plans and preferences and to relate possible differences to a variety of socioeconomic, psychological, and socio-structural factors.

In an attempt to move beyond simplistic explanations of migration intentions rooted in decontextualized economic rationality and to produce a contextually grounded assessment of these intentions, we focus our primary attention in this study on ethnicity. Ethnic differences have not been at the fore of the mainstream international migration literature because the migration flows that this literature typically studies, i.e., flows linking specific sending developing countries to specific countries in North America and Western Europe, tend to be either ethnically homogeneous or ethnically balanced. Not so in the case of the former Soviet Union: as we stated earlier, the post-Soviet net out-migration from Central Asia (as the historically preceding in-migration into the region) contained a disproportionate share of ethnic Russians and other ethnic groups of European roots. The ethnocultural and ethnopolitical discomfort has been said to be at the root of Central Asian Europeans' discontent and their excessive propensity to emigrate in the aftermath of independence (Nikolaev, 1994; Vitkovskaya, 1999). However, it is important to note that in the context of post-Soviet Central Asia, overt ethnic discrimination and harassment have been rare and therefore ethnic-specific discomfort could have affected Europeans' migration propensity indirectly, by magnifying their dissatisfaction with economic conditions and prospects (Radnitz, 2006a).

Both the actual or perceived disadvantage of a minority group and its ability and willingness to deal with that disadvantage through migration can change overtime. Thus, toward the beginning of this century, when the early post-Soviet outflow from Central Asia had ebbed, the excessive proclivity of the region's European residents toward migration may have diminished due to two factors. The first factor is the selective nature of post-Soviet migration: those Europeans who felt most uncomfortable with the changes induced by independence, were least integrated into Kyrgyzstani society, and/or had adequate economic and social resources for a move to Russia, did leave. Accordingly, those who stayed were largely less willing and/or less able to migrate. The second factor that may be altering the ethnic balance of migration is the growing migratory aspirations of indigenous groups, who may not contemplate a permanent move to Russia but may increasingly consider temporary or seasonal migration to earn cash and to remit it to their impoverished families back home. Yet, overall, greater proclivity to migrate among Europeans may still persist due primarily to what is defined in migration research as cumulative causation: prior migration flows create social networks at places of destination 
that provide information and other resources to potential new migrants, thus offsetting the costs of their moves (Massey, 1990). At the same time, the dwindling share of Europeans in the population of Central Asian nations, due both to the incessant stream of out-migration and to lower fertility, and the continuing indigenization of national politics, could fuel and even exacerbate Europeans' feelings of insecurity and exclusions and strengthen their migration intentions. Finally, state-level incentives for Europeans' emigration can also come from the receiving end, in the form of the Russian government's encouragement for selective "return of compatriots" (Russian Federation, 2006b).

The migration literature has devoted considerable attention to the role of marriage and childbearing in migration decision making. Thus it is often said that single and childless people are more inclined to labor migration (Jacobsen and Levin, 2000; Yang, 2000). From the migration decision-making perspective, studies typically posit that childbearing dampens the proclivity to migrate and, accordingly, individuals intent on migration postpone childbearing until after they reach their migration destinations. Besides this "disruption" mechanism, "selection" factors, such as lower desired fertility among potential migrants, are also entertained in the literature (Goldstein and Goldstein, 1983; Lindstrom and Saucedo, 2002; Chattopadhyay, White, and Debpuur, 2006). While a conflict between childbearing and migration is commonly assumed, one can also argue that the births of children can put pressure on the family's resources and force its members, usually men, to contemplate labor (temporary) migration as a potential source of income unmatched in the country of current residence. And some families with children may even consider migration in hopes of finding better life opportunities for their children in a foreign land.

With respect to marriage, the literature focusing on developing countries rarely separates marital union formation from childbearing. However, earlier research on Central Asia points to a possibility that for at least Europeans marriage not immediately followed by childbearing may constitute a type of migration unit that might be in a better position for overcoming the challenges of migration than individuals (Agadjanian, 1999; Agadjanian and Makarova, 2003). Again, this ethnically peculiar form of demographic adjustment to adversity, if indeed utilized, fits well conceptually with the minority-group status perspective.

An important segment of the migration literature deals with gender differences in migration motivations, decisions, and behavior (De Jong, Richter, and Isarabhakdi, 1996; De Jong, 2000; Kanaiaupuni, 2000). In the global migration flows men continue to outnumber women, and despite sizeable and rising migration of women in some regions and occupational niches (Chant, 1992; Zlotnik, 1995; Kofman, 1999; Kanaiaupuni, 2000), 
the part of the world on which we focus this analysis is still dominated by male migration (Laruelle, 2006). However, in most settings, gender differences are manifested mainly in temporary (seasonal) labor migration of individuals (Yang, 2000); permanent migration is more gender balanced for much of it is family based.

Another central matter in migration research is the role of migrationrelated social capital. We already mentioned how earlier migration flows might affect migration preferences of Europeans and, increasingly, of Asians. Having relatives and/or friends living in places of potential destination may encourage migration by reducing its perceived costs and inflating its expected benefits (Fuller, Lightfoot, and Kaltnuansilpa, 1990; Massey, 1990; Menjívar, 2000). Individuals' intentions to migrate may also be influenced by their friends and acquaintances who migrated before or intend to migrate (Epstein and Gang, 2006). However, it is still debatable whether relatives/friends living abroad encourage migration regardless of its objectives and desired duration. Group characteristics may also play a role. Thus, while it is plausible to expect that members of a group with a longer and more profuse migration experience, such as Europeans, would have greater migration-related social capital than members of a group whose collective migration experience is much more modest (the Kyrgyz), the relative importance of migration-related social capital for migration decisions may vary across the two types of groups. Yet, it could also be argued that Europeans, being a disadvantaged minority group whose proclivity to migration stems largely from perceived social vulnerability, might not need the "help" of migration-related social capital to develop intentions to migrate to the same degree as might members of a majority group, such as the Kyrgyz, whose well-being and opportunities are not compromised by their collective ascribed status.

Finally, migration choices and preferences may be influenced by individuals' perceptions of their socioeconomic and political environment at either migration origin or migration destination (Stinner and Van Loon, 1992; De Jong, Richter, and Isarabhakdi, 1996; De Jong, 2000). For a study like ours, which focuses on the sending context, individuals and social groups that perceive their existing personal and collective opportunities as being circumscribed by a hostile political system or an unfavorable structure of economic and social opportunities may develop and articulate stronger inclinations to migrate. Applied to our specific setting, it would imply not only that Europeans would have a more negative assessment of their community environment and collective opportunities than would the Kyrgyz and other Asians, but also that these factors would have a greater mediating effect on their intentions to migrate. 


\section{RESEARCH QUESTIONS AND HYPOTHESES}

Our conceptual model adapts the literature on migration intentions and behavior to the specific context of Kyrgyzstan, and more broadly to the historical, political, economic, ethnocultural, and migration context of post-Soviet Eurasia. With respect to ethnicity, the subject of our primary interest, we hypothesize that motivations for migration, while primarily economic, will vary in strength and nature between Asians and Europeans. Specifically, we expect that Russians and other Europeans will show greater inclination toward migrating than will the Kyrgyz and other Asians. These ethnic differences will be particularly pronounced when it comes to firm plans to migrate (as opposed to mere wishes or preferences to do so) and in intentions to move permanently rather than temporarily. As we anticipate that Europeans will be more inclined to permanent rather than temporary migration, we also expect them to be more predisposed toward undertaking family-based rather than individual moves. However, we also hypothesize that these ethnic differences will be largely, if not entirely, due to different perceptions of individual and family past economic achievements and current economic opportunities, of the social environment in the community of residence, and of the economic, political, and ethnic climate in Kyrgyzstan.

With respect to gender, we expect that men will exhibit greater propensity to migrate than women, but that gender differences will be mostly manifested in plans and wishes to migrate temporarily and individually, usually for work or study. Again, because of more traditional gender relations among the ethnic Kyrgyz and other indigenous Asian groups than among Russians and other Europeans, we also anticipate that the expected gender differences will be more pronounced among the former.

While our general expectation is that individuals in marital relationships may be less likely to plan or want to migrate, we also believe that this negative association will be mediated by childbearing. The research on ethnic-specific marriage patterns in Central Asia cited above leads us to expect that, controlling for childbearing, being in a marital union may be associated with higher proclivity to migrate among Europeans. Having children, on the other hand, should act as a deterrent to migration, as children considerably raise the cost of moving. Alternatively, one could hypothesize that parents' concern for the future of their offspring could increase their propensity to migrate permanently and with children or to migrate temporarily, to earn cash to support children back home. In either case, however, we have no basis to expect that the effects of childbearing on migration would differ between the two ethnic groups. 
With regard to social capital, we posit that migration-related social capital, such as having relatives in a foreign country or having friends who plan or wish to emigrate, will bolster proclivity to move abroad. Individuals endowed with migration-related social capital should be more likely to make firm plans to migrate and should also be more inclined to migrate permanently and to migrate with families than those with no such capital. Because of the ethnic history of migration from Kyrgyzstan, we expect that Europeans, on average, will possess more migration-related social capital. While this type of social capital should matter for both ethnic groups, we anticipate that it would be more influential for migration intentions among Asians than among Europeans as the latter can expect a friendlier reception in Russia regardless of their personal ties there and may need less encouragement from peers to contemplate a journey already taken by tens of thousands or their coethnics.

In contrast to migration-related social capital, migration-unrelated social capital at the current place of residence is expected to be negatively related to migration intentions, especially intentions to leave permanently and accompanied by other family members. Because we assume that migration-unrelated social capital is ethnically neutral, we do not anticipate its influence on migration intentions to be stronger among Asians than among Europeans.

Finally, we expect that intentions to migrate, especially to do so permanently and with family, will be influenced by individuals perceptions of wellbeing at the family, community, and national levels. We anticipate that Europeans will display more pessimistic assessments of trends in their families' well-being, of their community surroundings, and of the nation's conditions as a whole. The ethnic gap should be particularly wide in the assessment of prospects for own ethnic group. We expect, however, that these assessments would show a stronger association with intentions to migrate among Asians than among Europeans, as the latter's migration intentions may be more driven by the cumulative inertia of post-Soviet out-migration history and greater subjective attractiveness of Russia as the most likely destination.

\section{DATA AND METHODS}

\section{Data}

Our data come from a survey conducted in 2005, some three months after the so-called "Tulip" revolution that led to the ousting of president Akayev (Radnitz, 2006b) and right before the elections for his successor. The survey covered three parts of the country's north: Bishkek, Kyrgyzstan's capital city, 
and rural and urban areas of two northern oblasts (provinces) - Chui and Issyk-Kul, where the Kyrgyz are an absolute majority, the share of other Asians is small, but Russians and other Europeans still constitute a sizeable minority. The survey sample consisted of 1,535 men and women aged 18-29 divided equally among three sampling domains: Bishkek and the two oblasts. A three-stage cluster sample was used in each of the three domains: a village (urban cluster) was first selected with a probability proportional to size, then households were randomly selected in each village, and finally, one individual of the target age was randomly selected within each household. This procedure generally assured a balanced representation of sexes. In clusters where it yielded a sex imbalance, the underrepresented sex was oversampled. In each oblast, rural and urban areas were sampled separately. To allow for sound ethnic comparisons, in rural areas, where the Kyrgyz greatly predominate, the non-Kyrgyz population was oversampled by making the probability of a village selection inversely proportional to the share of its Kyrgyz population as recorded in the 1999 population census. Because this sampling approach led to an overrepresentation of non-Kyrgyz individuals in the rural subsamples, the sociodemographic and ethnocultural profile of the respondents cannot be considered a fully representative snapshot of the population of that part of Kyrgyzstan. The survey collected detailed information on household characteristics, respondents' demographic, economic, and cultural characteristics, marital history and spouse characteristics, health and reproduction, migration history and intentions, social networks, community characteristics, political involvement and attitudes, and gender attitudes.

\section{Methods}

Our analyses are centered on factors that shape migration intentions. The term intentions is used here to encompass both firm plans to migrate abroad and wishes to migrate abroad in the absence of such plans, but whenever appropriate, we explicitly distinguish between plans and wishes. We construe "plan" and "wish" as two types of migration intentions that are similar in essence but different in strength and maturity. First, we look at the ethnicspecific prevalence of plans and wishes to migrate and the motivations behind them. Further, we examine intentions (plans and wishes) to migrate abroad permanently or temporarily and intentions to migrate abroad with family members or to migrate without them (we include the few cases of respondents intending to migrate with friends and other nonrelatives in the "without family" category). 
We fit logistic regression for ordered outcomes to analyze the maturity of migration intentions, i.e., having firm plans to migrate; having wishes to migrate (but no firm plans); and having neither plans nor wishes to migrate. To examine ethnic differences in the outcomes and in factors shaping these outcomes, we fit three models: one for the entire sample, one for Asians only, and one for Europeans only. We present only the results of full models, i.e., models that contain all the covariates (we also test the impact of specific covariates on the strength of association between ethnicity and migration intentions, but for the sake of brevity, the details of these tests are not reflected in the tables included in this paper).

When considering intentions to migrate permanently or temporarily we do not separate plans from wishes to ensure a reasonable frequency distribution (the number of Asians who had firm plans to migrate permanently was too small) and consequently more robust statistical results. Unlike the tests of maturity of migration intentions, in the analysis of permanent vs. temporary migration intentions we follow previous studies (De Jong, Richter, and Isarabhakdi, 1996; De Jong, 2000) in using logistic regression for multiple unordered outcomes (multinomial logit model), with the outcome of interest taking three values: 1) neither planning nor wishing to migrate abroad; 2) planning or wishing to migrate abroad permanently; and 3) planning or wishing to migrate abroad temporarily. In a related test, we apply a similar modeling approach to examine variations in intentions to migrate with or without family members. Again, the outcome in the multinomial logit model can take three values: 1) neither planning nor wishing to migrate abroad; 2) planning or wishing to migrate abroad with at least one family member; and 3) planning or wishing to migrate abroad without any family members.

As in the case of the analyses of maturity of migration intentions, for each of the last two tests we fit three models - one for both ethnic group and one for each group separately - and include the same set of covariates. Ethnicity is our main predictor of interest. We compare two groups - Asians and Europeans. Although these are pan-ethnic constructs, in each of these groups one ethnicity overwhelmingly predominates. Thus, ethnic Kyrgyz constitute over ninety percent of the Asian group, with other indigenous ethnicities of Central Asia making up the rest. Ethnic Russians account for over four-fifths of the European subsample. Notably, just over ninety percent of the European respondents were born in Kyrgyzstan and another five percent of them moved to Kyrgyzstan before reaching their tenth birthday.

In addition to ethnicity, our main predictor of interest, all the models include gender, marital status (in formalized or not formalized marital union 
vs. not in union), and childbearing status (having at least one child vs. having no children). We use two measures of migration-related social capital: 1) whether or not respondent has a close relative abroad, which is an indicator of migrationrelated social capital at potential destinations; and 2) whether or not she/he has a personal network partner (a close or trusted person) who also intends to migrate abroad, which is an indicator of migration-related social capital at the place of current residence (it should be noted that the effect of the latter variable cannot be firmly interpreted in causal terms because the intention of network partners may be influenced by ego's intentions). As a relevant proxy for migrationunrelated social capital we use residence of close kin within a five-minute walk of respondent's home.

To account for perceptions of family well-being we use respondent's assessment of changes in family material well-being in the preceding twelve months. We do not include prospective assessments of family material well-being in the multivariate models because the corresponding survey questions may have been interpreted in connection with a family's intended migration, which would confound causality. We use three measures of community-level optimism: whether or not people in community of residence help one another (in respondent's opinion); whether or not respondent thinks that living conditions in community improved in the preceding twelve months; and whether or not she/he thinks that living conditions in community will improve in the following twelve months. Finally, two indicators of nation-level optimism are used: whether or not respondent believes that Kyrgyzstan's economic situation will improve after the presidential elections (scheduled for the month after the survey); and whether or not she/he believes that the situation of her/his own ethnic group will improve after the elections.

In addition to these predictors of interest, all the multivariate models control for sociodemographic characteristics defined and presented in Table 1, such as age, education (some or complete higher vs. less than incomplete higher), working status (currently employed or not), family material status approximated by automobile ownership, and area of residence (rural, town, or the capital city). We also control for migration in five years preceding the survey, as migration experience is said to be an important predictor of further migration intentions (De Jong, 1999; Yang, 2000).

The covariates used in the multivariate models and their breakdown by ethnicity - Asians vs. Europeans - are listed in Table 1. On sociodemographic characteristics, the only salient difference between the two groups was in migration experiences: Asians were much more likely to have migrated in the five years preceding the survey, reflecting mainly their greater involvement in 
TABLE 1

Survey Sample Characteristics by Ethnic Group (Percent Except for Age)

\begin{tabular}{lrrr}
\hline \hline Characteristic & All & Asians & Europeans \\
\hline Sociodemographic Characteristics & & & \\
$\quad$ Male & 49.3 & 47.1 & 53.0 \\
$\quad$ Age (mean) & 22.7 & 22.6 & 22.7 \\
$\quad$ Place of residence & 39.5 & 38.4 & 41.5 \\
$\quad$ Rural & 27.1 & 27.9 & 25.7 \\
$\quad$ Town & 33.4 & 33.7 & 32.8 \\
$\quad$ Bishkek (capital) & 33.3 & 34.3 & 31.6 \\
$\quad$ In a marital union (official or not) & 30.9 & 32.1 & 28.7 \\
$\quad$ Has at least one child & 38.2 & 38.8 & 37.1 \\
$\quad$ At least some university education & 45.3 & 43.5 & 48.6 \\
$\quad$ Currently works for income & 27.2 & 25.8 & 29.6 \\
Family has an automobile & 25.7 & 31.6 & 15.6 \\
$\quad$ Migrated since 2000 (regardless of destination) & & & \\
Social Capital Measures & & & \\
$\quad$ Migration-related social capital & 51.2 & 35.0 & 79.1 \\
$\quad$ Has a close relative abroad & 38.5 & 29.7 & 53.7 \\
$\quad$ Network partner wants to migrate & 33.4 & 34.5 & 31.6 \\
Migration-unrelated social capital & & & \\
$\quad$ Has a close relative living within 5 min. walk & & & \\
Embeddedness and Well-being Perceptions & 31.6 & 34.7 & 26.2 \\
$\quad$ Family-level & & & \\
$\quad$ Family material conditions improved in past year & 28.3 & 25.4 & 33.2 \\
$\quad$ Community-level & 34.5 & 40.8 & 23.6 \\
$\quad$ People do not help each other in community & & & \\
$\quad$ Living conditions in community will improve in next year & 39.7 & 44.3 & 31.7 \\
$\quad$ National-level & 29.6 & 37.3 & 16.3 \\
$\quad$ Economic situation will improve after the elections & 971 & 564 \\
$\quad$ Situation of own ethnic group will improve after the elections & &
\end{tabular}

internal (primarily rural-urban) migration. Not surprisingly, Europeans and Asians differed markedly on measures of migration-related social capital, with the former being much more likely to have a relative abroad or a personal network partner willing to migrate than the latter. On measures of embeddedness and well-being perceptions, the contrasts were also very pronounced. Asians were much more likely than Europeans to state that the material conditions of their families had improved in the year preceding the survey. The two groups held sharply contrasting views on quality of life and the future of their communities. A much larger share of Europeans thought that residents of their respective communities rarely or never help one another; Europeans were also much less optimistic about trends in living conditions in their communities in twelve months after the survey. A much higher percentage of Asians than Europeans believed that the economic situation in the country would improve after the presidential elections of July 2005. Yet the greatest divergence between 
TABLE 2

Plans and Wishes to Migrate Abroad (Percent)

\begin{tabular}{lrcc}
\hline \hline & All & Asians & Europeans \\
\hline Firm Plans to Migrate & 11.4 & 5.4 & 21.8 \\
Firm plans to migrate permanently & 7.3 & 1.8 & 16.7 \\
Firm plans to migrate temporarily & 4.1 & 3.6 & 5.1 \\
Firm plans to migrate with family & 6.4 & 1.9 & 14.2 \\
Firm plans to migrate without family & 5.0 & 3.5 & 7.6 \\
Wish to Migrate & 12.1 & 8.6 & 18.3 \\
Wish to migrate permanently & 7.2 & 3.5 & 13.7 \\
Wish to migrate temporarily & 4.9 & 5.1 & 4.6 \\
Wish to migrate with family & 7.6 & 4.5 & 12.9 \\
Wish to migrate without family & 4.5 & 4.0 & 5.3 \\
Intention to Migrate (Plan or Wish) & 23.5 & 14.0 & 40.1 \\
Intention to migrate permanently & 14.5 & 5.3 & 30.4 \\
Intention to migrate temporarily & 9.0 & 8.7 & 9.7 \\
Intention to migrate with family & 14.1 & 6.4 & 27.1 \\
Intention to migrate individually (without family) & 9.5 & 7.5 & 12.9 \\
\hline
\end{tabular}

Asians and Europeans was registered in their answers to the question on whether they expected the situation of their own ethnic group to improve after the elections: 37 percent of Asians expected such an improvement whereas only 16 percent of Europeans did.

\section{RESULTS}

\section{Intentions and Motivations for Migration}

Table 2 presents the overall distribution of migration intentions (plans and wishes) and the ethnic-specific breakdown of that distribution. Just over one-tenth of the survey respondents said that they had firm plans to migrate, with the overwhelming majority of them having Russia as their migration destination. The contrast between the two main ethnic groups was impressive, with only 5 percent of Asians having such plans, compared to over one-fifth of Europeans. Of those respondents who reported firm plans to migrate, about two-thirds intended to migrate permanently; here the gap between Asians and Europeans was particularly wide. Finally, ethnic differences are also apparent with regard to intentions to migrate with or without other family members: whereas Asian potential migrants were almost evenly split between those planning or wishing to migrate with at least one family member and those planning or wishing to migrate without family, among European potential migrants, the former group was more than twice as large as the latter. 
Figure I. Specific Reasons for Plans and Wishes to Migrate Abroad, by Ethnicity (Percent of All Stated Reasons)

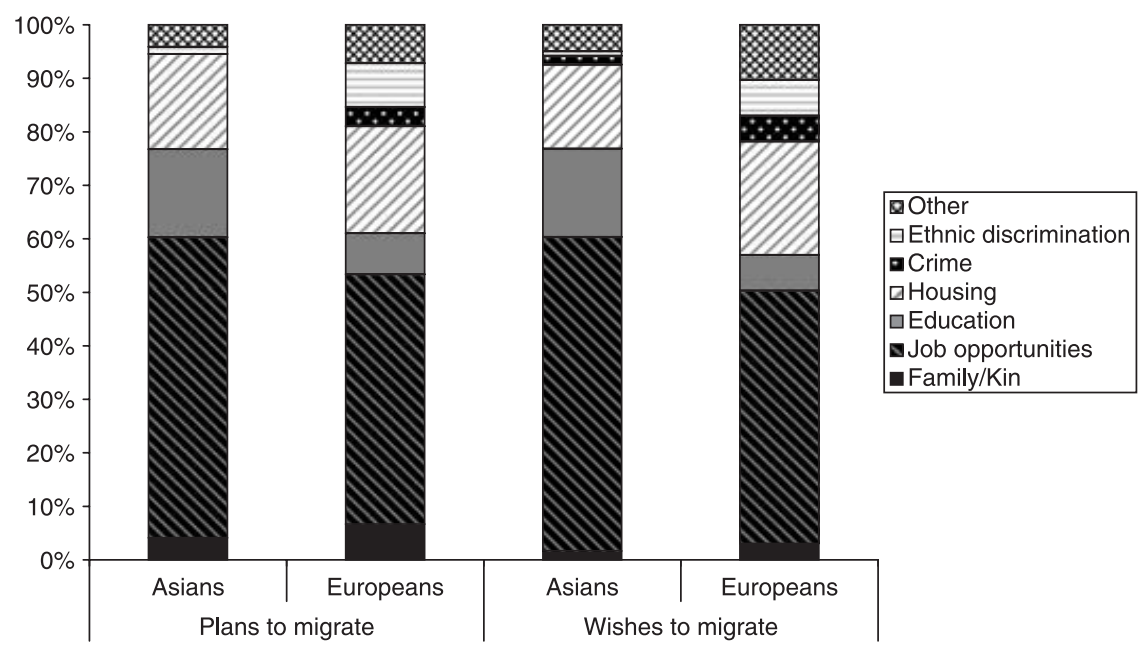

In addition to those who had firm plans to migrate, about 12 percent of the respondents said they would like to migrate abroad if the circumstances allowed (i.e., wished to migrate, in our definition). Over half of those who expressed a wish to migrate wanted to do so permanently. The ethnic gaps are somewhat smaller than in the case of firm plans but are still very wide. In all, almost a quarter of the survey respondents planned or wished to migrate abroad, this share reaching as high as 40 percent among Europeans. Supporting our expectation that Europeans would be much more inclined to want to migrate permanently, almost a third of Europeans planned or wished to leave Kyrgyzstan for good, whereas the corresponding fraction of Asians was only 5 percent. Interestingly, with respect to the share of those who planned or wished to go abroad temporarily (mainly to work or study), the two ethnic groups were very similar. Over a quarter of Europeans intended to migrate with at least one family member, compared to 13 percent whose intention was to migrate alone. In contrast, among Asians, those who wanted to move individually slightly outnumbered those who preferred to migrate with family members.

The ethnic-specific breakdown of reasons for planning and wishing to migrate abroad stated by the survey respondents is depicted in Figure I. Because respondents could pick as many reasons as they wanted, Figure I presents the relative number of occurrences of each reason in the total number of given reasons in each ethnic subsample. The distribution of reasons is rather 
similar between plans and wishes but varies somewhat between the two ethnic groups. In both groups and for both outcomes, the prospect of finding a better job strongly predominated. This reason seemed somewhat more common among Asians but it was also clearly the most important force behind Europeans' migration intentions. Interestingly, family motives were of great importance for neither group, even though these motives were invoked somewhat more often by Europeans than Asians. Housing problems and related expectations were another common consideration driving the migration intentions among both groups. Educational opportunities abroad were also prominent but were particularly so among Asians. Finally, as one would expect, ethnic discrimination was stated as a reason almost exclusively by Europeans, but in relative terms, that motivation was not of great importance even to them.

\section{Multivariate Results}

Maturity of Migration Intentions. The odds ratios from the logistic regression model for the three ordered outcomes - plans, wishes, and neither - are presented in Table 3; they are to be interpreted as the change in the maturity of migration intention caused by a unit increase in the value of corresponding predictors. The results of these tests generally confirm the bivariate patterns displayed and discussed earlier. The ethnic differences are stark, even after the addition of other covariates. There are no net gender differences in either ethnic group. Having a child discourages migration, but does so only among Asians. On the contrary, being in a union, net of childbearing, increases migration inclinations, but in statistically convincing terms, does so only among Europeans. Migration-related social capital retains a strong impact, but having close kin abroad has a stronger effect among Europeans while having a network partner intending to migrate has a stronger impact on the degree of migration intentions among Asians. In contrast, migration-unrelated social capital proves largely irrelevant. The expectation of improvement in community conditions tends to weaken migration intentions but seems to do so primarily among Asians (the corresponding parameter estimate is, however, only marginally significant). Neither the nation-level economic optimism nor expectations regarding the situation of own ethnic group shows any effect on migration intentions.

The effects of the controls are also noteworthy. Recent migration tends to significantly dampen migration intentions among Asians, but the positive effect of recent migration in the European model is not statistically significant. Interestingly, Bishkek residence significantly increases proclivity to 
TABLE 3

Intentions to Migrate Abroad, Ordered Logit (Odds Ratios)

\begin{tabular}{|c|c|c|c|}
\hline Predictors and Controls & All & Asians & Europeans \\
\hline \multicolumn{4}{|l|}{ Predictors } \\
\hline Asians (Europeans) & $0.438^{* *}$ & & \\
\hline Man (woman) & 0.995 & 0.928 & 1.058 \\
\hline In marital union (not in union) & $1.599^{*}$ & 1.384 & $1.816^{*}$ \\
\hline Has at least one child ${ }^{\mathrm{a}}$ (has no children) & $0.558^{* *}$ & $0.367^{* *}$ & 0.645 \\
\hline Has at least one close relative abroad (has no close relatives abroad) & $2.852^{* *}$ & $2.338^{* *}$ & $3.776^{* *}$ \\
\hline At least one network partner wants to migrate (no partner who wants to migrate) & $2.521^{* *}$ & $3.248^{* *}$ & $1.908^{* *}$ \\
\hline At least one close relative lives within 5 min. walk (no relatives within 5 min. walk) & 0.863 & 0.737 & 0.922 \\
\hline People do not help one another in community (other opinions) & 1.074 & 0.970 & 1.100 \\
\hline Material conditions of family improved in past year (other opinions) & 0.904 & 1.017 & 0.791 \\
\hline Living conditions in community will improve next year (other opinions) & $0.690^{*}$ & $0.684^{\dagger}$ & 0.700 \\
\hline Situation of own ethnic group will improve after elections (other opinions) & 0.940 & 0.993 & 0.878 \\
\hline Country's economic conditions will improve after elections (other opinions) & 0.862 & 1.009 & 0.772 \\
\hline \multicolumn{4}{|l|}{ Controls } \\
\hline Age & 1.021 & 1.055 & 0.993 \\
\hline Lives in town ${ }^{\mathrm{b}}$ & 0.813 & 0.745 & 0.815 \\
\hline Lives in Bishkek ${ }^{\mathrm{b}}$ & $1.378^{*}$ & $2.410^{* *}$ & 0.837 \\
\hline At least some higher education (no higher education) & $1.365^{*}$ & 1.385 & 1.177 \\
\hline Gainfully employed (not employed) & 1.071 & 0.902 & 1.023 \\
\hline Household owns automobile (does not own automobile) & 1.034 & 1.041 & 0.815 \\
\hline Migrated at least once since 2000 (did not migrate since 2000) & 0.844 & $0.503^{* *}$ & 1.322 \\
\hline Likelihood ratio chi-square & $308.4^{* *}$ & $150.1^{* *}$ & $65.5^{* *}$ \\
\hline Number of cases & 1,535 & 971 & 564 \\
\hline
\end{tabular}

Notes: Reference categories in parentheses.

ancludes women who are currently pregnant.

b"Lives in village" is reference.

Significance level: ${ }^{*} \mathrm{p} \leq .05,{ }^{* *} \mathrm{p} \leq .01,{ }^{\dagger} \mathrm{p} \leq .1$. 
migrate relative to rural residence, but this effect is present only among Asians. In the overall model, those with higher education were, ceteris paribus, more inclined to migrate than those without it. Finally, employment and household affluence (automobile ownership) show no association with migration intentions.

Permanent vs. Temporary Migration Intentions. We now look at migration intentions from the perspective of its expected or desired duration. With the earlier-mentioned caveats in mind, we compare the two groups on whether the stated intentions (plans and wishes combined) are for permanent migration or for temporary migration. The results of the multinomial logit model are shown in Table 4. For an easier grasp, the results are broken down by pairs of values of the outcome variable: intentions to migrate permanently vs. lack of any intentions to migrate; intentions to migrate temporarily vs. lack of any intentions to migrate; and intentions to migrate permanently vs. intentions to migrate temporarily. As the results indicate, adjusting for other factors, Asians' odds of intending to migrate permanently, relative to not intending to migrate at all, are just over one-quarter of Europeans'. Asians are also significantly less likely than Europeans to intend to migrate permanently relative to intending to migrate temporarily. However, no ethnic difference in the odds of intending to migrate temporarily relative to not intending to migrate can be detected once the covariates are added.

Gender, again, shows no influence. Being in a union (net of childbearing experience) again stands out as a catalyst for permanent migration - in relation to either intending to stay or intending to migrate temporarily, but does so strongly and significantly only among Europeans. At the same time, preference for temporary migration is not affected by marital status in either group. As already transpired in the previous test, childbearing is not an important factor in migration intentions among Europeans. Among Asians, the negative effect of having a child on migration intentions is more pronounced but is statistically significant only with respect to the intention to migrate temporarily vs. no intention to migrate.

Having kin abroad increases the likelihood of intending to migrate both permanently and temporarily. In the choice between these two alternative migration intentions, having relatives who live outside Kyrgyzstan tilts the preference toward permanent migration but this tendency is statistically significant only among Asians. In both groups, having network partners who plan or wish to migrate abroad increases the odds of intending to migrate either permanently or temporarily, but the effects are larger among Asians. At the same time, in neither ethnic group, having network partners with migration intentions matters for the choice between permanent and temporary migration. 
TABLE 4

Intentions to Migrate Abroad Permanently or Temporarily or Not to Migrate at All, Multinomial Logit (Odds Ratios)

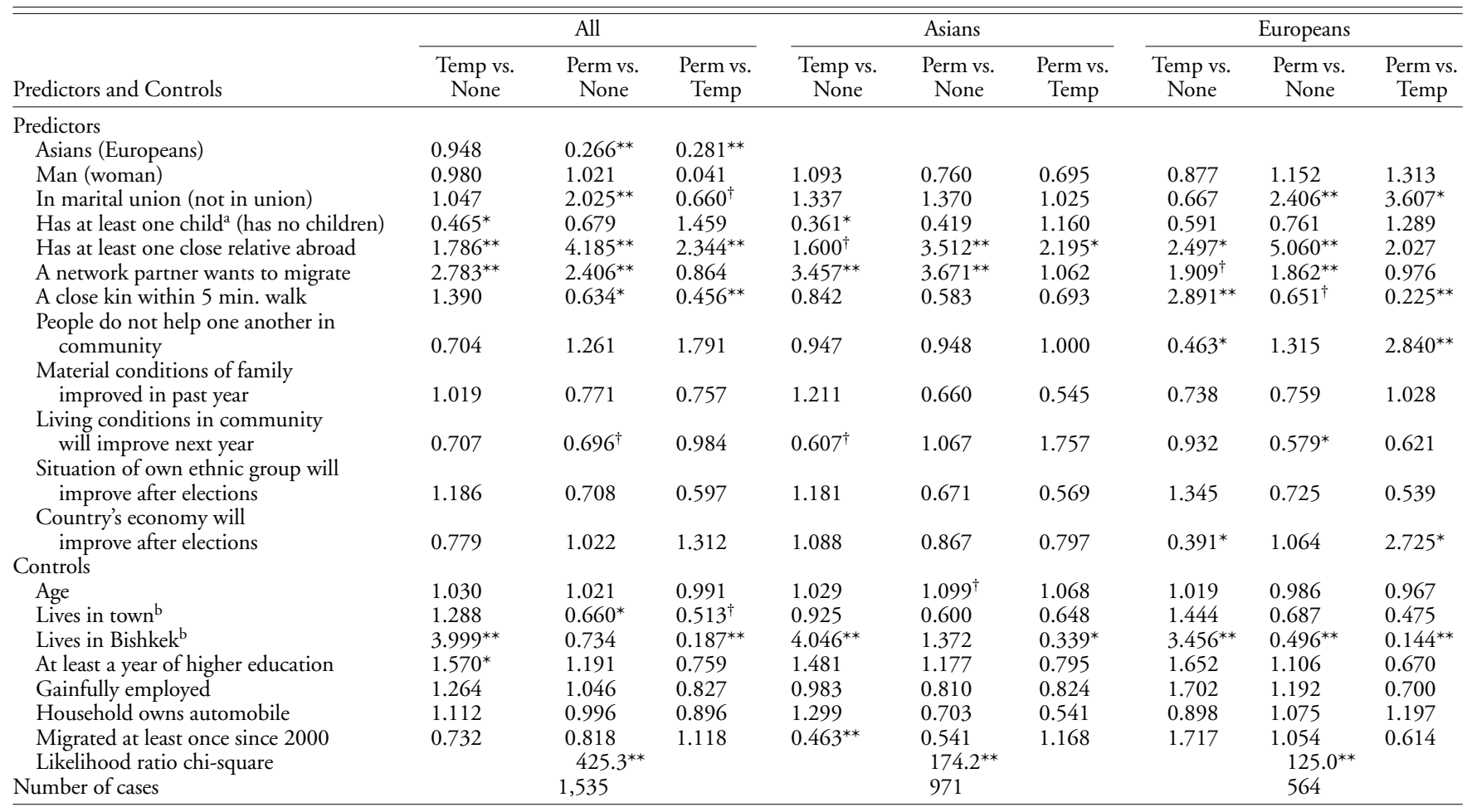

Notes: Reference categories in parentheses.

${ }^{a}$ Includes women who are currently pregnant.

b"Lives in village" is reference.

Significance level: ${ }^{*} \mathrm{p} \leq .05,{ }^{* *} \mathrm{p} \leq .01,{ }^{\dagger} \mathrm{p} \leq .1$. 
The presence of relatives in the neighborhood decreases the propensity toward permanent migration, but this effect, especially on opting for permanent vs. temporary migration, is statistically noticeable only among Europeans. Interestingly, among this group, the proximity of relatives encourages the intention to migrate temporarily vs. not migrating. The assessment of recent trends in family economic well-being seems irrelevant to either type of migration intention. The perception of community-level social support does not matter for Asians, but among Europeans the lack of community support, while not encouraging permanent migration per se, does make such migration a more attractive option than temporary migration. The expectation of improving economic conditions in the community of residence shows a marginally significant negative effect on Asians' proclivity to migrate temporarily; in comparison, among Europeans it discourages permanent migration. The perception of macroeconomic changes to come after the presidential elections, while irrelevant to migration intentions of Asians, does affect these intentions among Europeans: the expectation of positive improvements discourages temporary migration, relative to not migrating, but at the same time, encourages permanent migration, relative to temporary migration. Finally, the perception of future changes in the situation of own ethnic group shows no significant impact on intended duration of migration.

Among other factors, prior migration does not affect Europeans' but does dampen Asians' temporary migration intentions, relative to not wanting to migrate. Town residence, relative to living in the countryside, tends to diminish inclination toward permanent migration, but these effects are not statistically significant in the ethnic-specific models. In contrast, Bishkek residence significantly strengthens both groups' propensity for temporary migration. Finally, age, education, employment, and affluence show few if any effects.

Intentions to Migrate with or without Family Members. In our last set of tests, we fit multinomial logit models to examine intentions to migrate with family members, without them, and the lack of stated intention to migrate. Because this outcome overlaps somewhat with the one we just discussed, some of the results of this group of models parallel those of the previous tests. These results are presented in Table 5. Asians are significantly less likely than Europeans to report an intention to migrate with family members relative to reporting no intention to migrate: the corresponding odds for Asians are less than one-fifth of the odds of Europeans. Asians are also significantly more likely to opt for family migration vs. nonfamily migration, although the ethnic gap is less pronounced than in the previous pair. At the same time, the difference between 
TABLE 5

Intentions to Migrate Abroad with or without Family Members, Multinomial Logit (Odds Ratios)

\begin{tabular}{|c|c|c|c|c|c|c|c|c|c|}
\hline \multirow[b]{2}{*}{ Predictors and Controls } & \multicolumn{3}{|c|}{ All } & \multicolumn{3}{|c|}{ Asians } & \multicolumn{3}{|c|}{ Europeans } \\
\hline & $\begin{array}{l}\text { With Fam. } \\
\text { vs. None }\end{array}$ & $\begin{array}{l}\text { W/out Fam. } \\
\text { vs. None }\end{array}$ & $\begin{array}{l}\text { With Fam. } \\
\text { vs. W/out } \\
\text { Fam. }\end{array}$ & $\begin{array}{l}\text { With Fam. } \\
\text { vs. None }\end{array}$ & $\begin{array}{l}\text { W/out Fam. } \\
\text { vs. None }\end{array}$ & $\begin{array}{l}\text { With Fam. } \\
\text { vs. W/out } \\
\text { Fam. }\end{array}$ & $\begin{array}{l}\text { With Fam. } \\
\text { vs. None }\end{array}$ & $\begin{array}{l}\text { W/out Fam. } \\
\text { vs. None }\end{array}$ & $\begin{array}{l}\text { With Fam. } \\
\text { vs. W/out } \\
\text { Fam. }\end{array}$ \\
\hline \multicolumn{10}{|l|}{ Predictors } \\
\hline Asians (Europeans) & $0.184^{* *}$ & 0.724 & $0.429^{* *}$ & & & & & & \\
\hline Man (woman) & 0.887 & 1.137 & 0.780 & 1.145 & 0.863 & 1.327 & 0.825 & 1.559 & $0.529^{\dagger}$ \\
\hline $\begin{array}{l}\text { In marital union } \\
\text { (not in union) }\end{array}$ & $2.580^{* *}$ & 0.571 & $4.515^{* *}$ & $4.259^{* *}$ & $0.288^{*}$ & $14.800^{* *}$ & $2.282^{* *}$ & 0.872 & $2.618^{\dagger}$ \\
\hline $\begin{array}{l}\text { Has at least one child } \\
\text { (has no children) }\end{array}$ & 0.885 & $0.180^{* *}$ & $4.919^{* *}$ & 0.532 & $0.151^{* *}$ & 3.518 & 0.999 & $0.185^{* *}$ & $5.411^{* *}$ \\
\hline $\begin{array}{l}\text { Has at least one } \\
\text { close relative abroad }\end{array}$ & 3.483 & $2.148^{* *}$ & $1.621^{\dagger}$ & $3.237^{* *}$ & 1.537 & $2.106^{\dagger}$ & $3.635^{* *}$ & $4.944^{* *}$ & 0.735 \\
\hline $\begin{array}{l}\text { to migrate } \\
\text { A close kin within }\end{array}$ & $2.230^{* *}$ & $3.295^{* *}$ & 0.677 & $2.831^{* *}$ & $4.574^{* *}$ & 0.619 & $1.709^{* *}$ & $2.587^{* *}$ & 0.661 \\
\hline 5 min. walk & 0.843 & 0.895 & 0.942 & 0.678 & 0.689 & 0.985 & 0.950 & 0.963 & 0.987 \\
\hline $\begin{array}{l}\text { People do not help } \\
\text { one another } \\
\text { in community }\end{array}$ & 0.877 & 1.299 & 0.675 & 0.705 & 1.297 & 0.544 & 0.929 & 1.246 & 0.745 \\
\hline $\begin{array}{l}\text { Material conditions } \\
\text { of family improved } \\
\text { in past year }\end{array}$ & $0.688^{*}$ & 1.207 & $0.570^{*}$ & $0.549^{\dagger}$ & 1.437 & $0.382^{*}$ & 0.683 & 0.963 & 0.709 \\
\hline
\end{tabular}




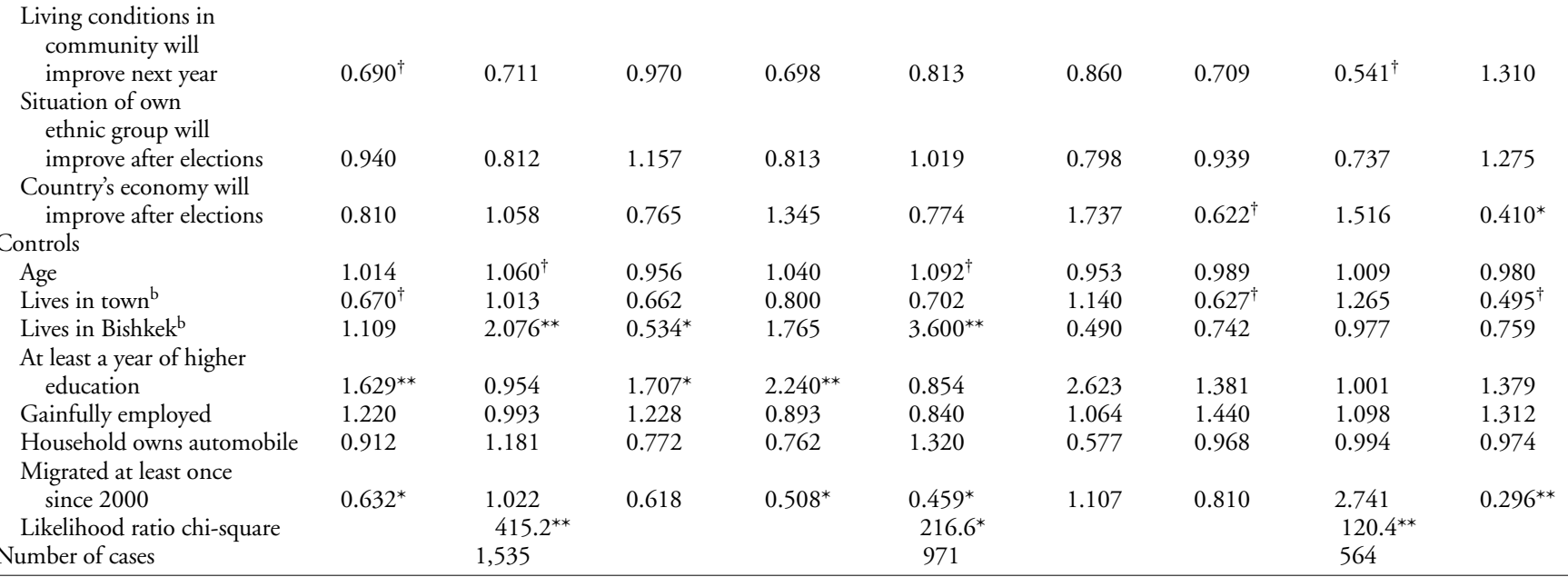

Notes: Reference categories in parentheses.

ancludes women who are currently pregnant.

b"Lives in village" is reference.

Significance level: ${ }^{*} \mathrm{p} \leq .05,{ }^{* *} \mathrm{p} \leq .01,{ }^{\dagger} \mathrm{p} \leq .1$. 
Asians and Europeans in intending to migrate without family members relative to not intending to migrate is much smaller and statistically not significant (similarly to the differences in intentions to migrate temporarily vs. not migrating discussed earlier).

The effects of the other covariates in the overall and ethnic-specific models are generally congruent with those in the previous set of tests, which is not surprising if we consider that the intentions of migrating with family members or without them are related to the intentions of migrating permanently or temporarily, respectively. However, some informative distinctions between the two tests can be noted. Not surprisingly, the most notable differences are in the effects of being in a marital union and of having a child. Thus, in the entire sample, being in a marital union, net of other factors, is conducive to migration with family members. However, this tendency is manifested much more forcefully among Asians than among Europeans. Moreover, among Asians, marital union significantly discourages individual migration, while among Europeans this effect is absent. In the overall sample, having at least one child discourages migration without family, but when it comes to the choice of whether to migrate with family members or without them, this effect is statistically significant only among Europeans. Among other notable differences from the picture presented in Table 5, a perceived improvement in family material situation in the previous year tends to diminish the preference for family-based moves, but the corresponding statistical effects are noticeable only among Asians. Relatives' proximity (nonmigration social capital) shows no effect on either option in either ethnic group, and the assessment of community's social fabric and economic prospects proves largely irrelevant as well.

\section{DISCUSSION AND CONCLUSION}

Growing interconnections in a rapidly globalizing world fueled and cemented by intensifying and diversifying international migration movements are often viewed as key engines of transnationalization (Schiller, Basch, and Blanc, 1995; Faist, 2000). Although post-Soviet Eurasia's transnational space has formed through an unusual trajectory - a separation of administrative entities previously constituting one country rather than a rapprochement of sovereign nations it is a transnational space par excellence. Forged by decades and even centuries of political, economic, and cultural interdependencies, redefined but not eliminated after the dissolution of the USSR, this space is bound together by myriads of individual, economic, cultural, and political ties. 
Our study produced some illuminating insights into the forces that shape this transnational space by investigating different dimensions of migration plans and wishes of young adults in Kyrgyzstan. First and foremost, it demonstrated a wide gulf in migration intentions between Asian and European youths. Europeans were clearly more migration-inclined, and the ethnic gulf remained very salient even after controlling for socioeconomic, sociopsychological, and social capital characteristics. As we hypothesized, Europeans were also more likely than Asians to choose permanent migration over temporary migration and family migration over nonfamily migration, regardless of other factors. In contrast, ethnic differences in propensity for temporary migration vs. no migration and for individual migration vs. no migration were fully explained by other characteristics. Hence, while the divergence in the types of migration preferences between the two ethnic groups is clearly taking shape, it would be inaccurate to conclude that Europeans tend toward migrating permanently and with families whereas Asians prefer migrating temporarily and individually. Instead, the results suggest that by the middle of the current decade, Asians, ceteris paribus, had caught with Europeans in proclivity toward temporary and individual migration (usually meant for short-term work or study) but were still much less inclined than Europeans to opt for permanent and family-based migration.

Contrary to our expectation, proclivity to migrate showed little, if any, variation by gender either within or across the ethnic boundaries. Most interestingly, gender differences were generally absent in the type of migration preferences in which they would be intuitively most plausible: temporary vs. permanent migration and family vs. individual migration. Marriage and childbearing, on the other hand, showed instructive effects on migration intentions that generally aligned with our hypotheses. Thus, being in a union, net of childbearing, increased the maturity of migration intentions among Europeans but had no statistically significant effect among Asians. This finding conforms to the earlier discussed pattern observed in Kazakhstan (Agadjanian, 1999) and may reflect a distinctive migration strategy among the nonnative ethnic segments of the population. Yet at the same time, marital status was associated with higher proclivity to migrate accompanied by family members, relative to not migrating, among both groups but especially among Asians. Ethnic-specific meanings and roles of marriage and their effects on migration intentions, therefore, require further investigation.

As we expected, childbearing tended to discourage migration intentions. However, we also detected important ethnic differences in this association. Having a child exerted an overall negative effect on migration intentions, but 
this effect was statistically detectable only among Asians. We did not find any straightforward support for the alternative hypothesis, i.e., that childbearing might encourage migration for the benefit of children. In fact, we detected a negative effect of having a child on the intention to migrate temporarily among Asians, and on the intentions to migrate without family members among both groups. At the same time, in neither ethnic group were the odds of intending to migrate with family, relative to not intending to migrate at all, affected by childbearing. Yet, having a child tended to strengthen greatly Europeans' preference for family-based migration over individual migration, despite the lack of any association between childbearing and intended duration of migration.

Our analyses confirmed the importance of migration-related social capital. As we hypothesized, possessing such capital, both at potential destinations and in places of current residence, strengthens migration intentions and increases proclivity to migrate permanently and to do so with family members. Not surprisingly, Europeans proved more endowed with migration-related social capital. Yet the ethnic patterns in the effect of that capital on migration intentions did not align fully with our expectation that migration-related social capital would matter more for Asians. Moreover, our analysis illustrated the differences between the roles of migration-related social capital at origin and at destination. Thus, having network partners who wished to migrate abroad (social capital at origin) indeed had a stronger effect on migration intentions of Asians than of Europeans. In contrast, having relatives who resided abroad (social capital at destination) seemed to affect Europeans' migration intentions to a greater degree. Yet, having relatives abroad was associated with a stronger preference for permanent over temporary migration and (to a lesser extent) for family-based over individual migration. This association, as our hypothesis predicted, was statistically more convincing among Asians than among Europeans. Unlike migration-related social capital, migration-unrelated social capital did not differ much between the two groups. As we anticipated, this type of social capital did not affect the maturity of migration intentions nor did it show any association with the intended or preferred composition migration. Unexpectedly, however, in the analysis of intended duration, relatives' proximity tended to deter Europeans, and only Europeans, from intending to migrate permanently and encouraged their intentions to migrate temporarily.

The two groups of surveyed young adults had very distinct assessments of both their immediate milieu and their broader societal environment: invariably Asians saw family, community, and country conditions and prospects in a more positive light than did Europeans. Yet, propensity for migration, 
however it is measured, did not quite show the pattern of ethnic differences that we had anticipated. Thus, Asians did not display any stronger association between the perception of recent trends in family material well-being and the strength of migration intentions or its intended duration than did Europeans, even though among Asians the positive assessment of these trends tended to dampen the intention to migrate accompanied by family members.

With respect to maturity of migration intentions, the expectation of improving conditions in community of residence had a somewhat stronger effect among Asians, supporting our expectation. In regard to intended duration, this expectation influenced both groups but did so differently - discouraging permanent migration among Europeans, while possibly discouraging temporary migration among Asians. Migration intentions proved largely impervious to expectations for the short-term economic future of Kyrgyzstan, and contrary to our hypothesis, whenever a statistically significant effect of that variable was observed, it concerned mainly Europeans. Finally, also contrary to our hypothesis, expectations regarding the prospects for respondent's ethnic group showed practically no association with any of the investigated dimensions of migration intentions.

The age group on which our study focused represents a qualitatively new generation of Kyrgyzstan's population - the first generation that came of age in the independent Kyrgyz Republic. It also represents a new generation of migrants. The earlier generation of migrants, having grown up and spent much of their lives in the Soviet Union, reacted "with their feet" to its demise. Today, the Soviet Union and the massive exodus from Central Asia surrounding its collapse are increasingly becoming facts of the past. Yet, migration intentions of the new generation of Kyrgyzstanis, fueled by the economic stagnation and political uncertainties, are strong. Also, like a generation earlier, these intentions are disproportionately prevalent among the nonnative minorities, primarily ethnic Russians and other Europeans. Migration offers minorities who are disadvantaged in a social system an option for mitigating and even eliminating their disadvantage: rather than trying to labor their way through the system's adversities, they get out of the system altogether. As Europeans' insecurities have lingered, so has their elevated proclivity to migrate, including for permanent settlement in foreign lands. Moreover, the earlier wave of migrants may have helped increase the appeal for the new generation of potential migrants, who can (or at least expect to) rely on their successful predecessors' advice and assistance. However, this is just one part of the story told in this study. Our analyses also shed light on the ideational dynamics underlying the rising migration tide among Kyrgyzstan's indigenous population, which differs considerably from Europeans' migration both in nature and antecedents. 
It is important to emphasize, however, that individual motives behind both Europeans' and Asians' migration intentions are remarkably similar as they are dominated by a quest for better economic opportunities (see Figure I). The literature on early post-Soviet out-migration from Central Asia may leave an impression that Europeans' emigration was a stampede of refugees fleeing ethnic abuse and persecution. It was hardly the case in the first post-Soviet years and is certainly not the case today. In fact, our study, while producing unmistakable evidence of greater ethnopolitical discontent among Europeans compared to Asians, did not detect any effect of this discontent on propensity for migrating. This finding agrees with evidence from a recent study in neighboring Uzbekistan (Radnitz, 2006a).

Our study also shows that the relative optimism of Asian young men and women (as attested by data presented in Table 1) has little bearing on their migration intentions. In fact, the strength and longevity of this optimism are questionable too. Abundant anecdotal evidence and our own field observations in Kyrgyzstan suggest that the hopes generated by the 2005 Tulip revolution, especially among the Kyrgyz youth (Khamidov, 2006) quickly wilted. No real economic reforms have been attempted and political instability has persisted (Radnitz, 2006b). In the meantime, the robustly growing economies of Russia and Kazakhstan beacon with opportunities that override the rising xenophobia in those two major destinations of Kyrgyzstan's migrants. Destinations outside the former Soviet Union are also becoming increasingly popular.

It was not an objective of this study to examine how migration intentions are actually implemented. Migration intentions, as stated by individuals, are often ambivalent and conditional, especially in circumstances of great uncertainty about the future (Gardner et al., 1986; Uehling, 2002). Yet, studies do point to a strong association between migration intentions and actual migration (De Jong et al., 1985; De Jong, 1999), even though migration intentions may be better predictors of permanent than temporary moves (De Jong, 2000). Economic stagnation at home and opportunities abroad, and the disenchantment and hopes that they generate, will continue to stimulate the migration flow from Kyrgyzstan. Although this flow contains a sizeable - and increasing - share of the country's titular ethnic group, the Kyrgyz, as well as other groups native to the Central Asian region, the migration potential remains particularly high among Europeans. In that group, the effects of economic malaise are compounded by those of political and cultural insecurities and discomfort; together, these factors "push" Europeans out of Kyrgyzstan.

No less important, however, are the "pull" factors. We already mentioned the importance of the cumulative momentum of European out-migration. 
This momentum is maintained by the legal and political context of immigrants' reception in host societies, especially in the Russian Federation. Thus the Russian government, apparently driven by concerns about low fertility, high mortality, and the resulting decline of Russian population, officially welcomes the "return" to Russia of "compatriots," i.e., ethnic Russians and other "Russian speakers," living abroad (Russian Federation, 2006b). Although it remains to be seen whether the Russian government's pledges to support the return of "compatriots" to Russia will materialize, the widely publicized promises of resettlement and employment assistance are likely to have an effect on their de facto primary target - ethnic Russians and other "Russian-speaking" groups in the former Soviet republics of Central Asia and the Caucasus. At the same time, the Russian Federation's immigration regulations aimed directly or indirectly at the Asian migrant groups remain controversial (e.g., Russian Federation, 2006a), and the public perception of migrants of Central Asia's and Caucasus's indigenous ethnic stock has been consistently - and increasingly - negative (Alexseev, 2007; Economist, 2007b).

Due to the combination of these factors, Europeans are likely to retain a disproportionate presence in the out-migration flow from Kyrgyzstan for years to come. The future will show whether the excessive out-migration of Europeans will eventually run its course because of the demographic exhaustion of that group or because of rising economic prosperity and ethno-political stability in Kyrgyzstan.

\section{REFERENCES}

Abazov, R.

1999 "Economic Migration in Post-Soviet Central Asia: The Case of Kyrgyzstan.” PostCommunist Economies 11(2):237-252.

Agadjanian, V.

1999 "Post-Soviet Demographic Paradoxes: Ethnic Differences in Marriage and Fertility in Kazakhstan." Sociological Forum 14(3):425-46.

—, and E. Makarova

2003 "From Soviet Modernization to Post-Soviet Transformation: Understanding Marriage and Fertility Dynamics in Uzbekistan." Development and Change 34(3):447-473.

Alexseev, M.

2007 "Nationhood Vigilantism in the Global Semi-Periphery: Migration and Ethnoreligious Hostility in Russia." In Security Challenges in the Post-Soviet Space: European and Asian Perspectives. Ed. A. Eberhardt and A. Iwashita. Warsaw and Sapporo: Polish Institute of International Affairs and Slavic Research Center, Hokkaido University. Pp. 275-302.

Anderson, B., and B. Silver

1989 "Demographic Sources of the Changing Ethnic Composition of the Soviet Union." Population and Development Review 15(4):609-656. 
Azrael, J., E. A. Payin, K. A. McCarthy, and G. Vernez, ed.

1996 Cooperation and Conflict in the Former Soviet Union: Implications for Migration. Santa Monica, CA: RAND.

Ball, B., and G. Demko

1978 "Internal Migration in the Soviet Union." Economic Geography 54(2):95-114.

Boyd, M.

1989 "Family and Personal Networks in International Migration: Recent Developments and New Agendas." International Migration Review 23(3):638-670.

Chant, S., ed.

1992 Gender and Migration in Developing Countries. London: Belhaven Press.

Chattopadhyay, A., M. White, and C. Debpuur

2006 "Migrant Fertility in Ghana: Selection versus Adaptation and Disruption as Causal Mechanisms." Population Studies 60(2):189-203.

Chernova, E. P.

1977 “The Kyrgyz Soviet Socialist Republic." In The Population of Union Republics. Ed. T. V. Ryabushkin. Moscow: Statistika. Pp. 225-243 (in Russian).

Cokgezen, $\mathrm{M}$.

2004 "Corruption in Kyrgyzstan: The Facts, Causes and Consequences." Central Asian Survey 23(1):79-94.

De Jong, G. F.

2000 "Expectations, Gender, and Norms in Migration Decision-Making." Population Studies 54:307-319.

1999 "Choice Processes in Migration Behaviour." In Migration and Restructuring in the U.S. Ed. K. Pandit and S. D. Withers. New York, NY: Rowman and Littlefield. Pp. 273-292. K. Richter, and P. Isarabhakdi

1996 "Gender, Values, and Intentions to Move in Rural Thailand." International Migration Review 30(3):748-770.

- , et al.

1985 "Migration Intentions and Behavior: Decision Making in a Rural Philippine Province." Population and Environment 8(1-2):41-62.

[The] Economist

2007a "Steppe Change: Central Asian Migration." The Economist, March 24, 382(8521):47.

2007b "Market Forces: Russia’s Sensible and Less Sensible Migration Policies." The Economist, January 18, 382(8512):61.

Epstein, G. S., and I. N. Gang

2006 "The Influence of Others on Migration Plans." Review of Development Economics 10(4):652-665.

Faist, T.

2000 The Volume and Dynamics of International Migration and Transnational Social Spaces. Oxford: Oxford University Press.

Fuller, T. D., P. Lightfoot, and P. Kaltnuansilpa

1990 "Urban Ties of Rural Thais." International Migration Review 24:534-562.

Gardner, R. W., G. F. De Jong, F. Arnold, and B. V. Carino

1986 "The Best-Laid Schemes: An Analysis of Discrepancies between Migration Intentions and Behavior." Population and Environment 8(1-2):63-77. 
Goldstein, A., and S. Goldstein

1996 "Migrants' Motivations and Outcomes: Permanent and Temporary Migrants Compared." In China: The Many Facets of Demographic Change. Ed. A. Goldstein and F. Wang. Boulder, CO: Westview Press. Pp. 673-701.

- S. Goldstein, and S. Gu

1993 "Determinants of Permanent and Temporary Mobility in Hubei Province, PRC." In International Population Conference: Montreal 1993. Vol. 2. Liege, Belgium: International Union for the Scientific Study of Population [IUSSP]. Pp. 85-101.

Goldstein, S., and A. Goldstein

1983 Migration and Fertility in Peninsular Malaysia: An Analysis Using Life History Data. Santa Monica, CA: RAND.

Guilmoto, C. Z.

1998 "Institutions and Migration: Short-Term versus Long-Term Moves in Rural West Africa." Population Studies 52:85-104.

Heleniak, T.

1997 "The Changing Nationality Composition of the Central Asian and Transcaucasian States." Post-Soviet Geography and Economics 38(6):357-378.

Huskey, E.

1997 "Kyrgyzstan: A Case Study for Conflict Potential." The Soviet and Post-Soviet Review 24(3):229-249.

Iontsev, V. A.

1998 "International Population Migration: Russia and the Modern World." Sotsiologicheskie Issledovaniya 6:38-48 (in Russian).

Jacobsen, J. P., and L. M. Levin

2000 "The Effects of Internal Migration on the Relative Economic Status of Women and Men." Journal of Socio-Economics 29:291-304.

Kanaiaupuni, S. M.

2000 "Reframing the Migration Question: An Analysis of Men, Women and Gender in Mexico." Social Forces 78(4):1311-1347.

Khamidov, A.

2006 "Kyrgyzstan's Revolutionary Youth: Between State and Opposition." SAIS Review 26(2):85-93.

Kofman, E.

1999 "Female 'Birds of Passage' a Decade Later: Gender and Immigration in the European Union.” International Migration Review 33(2):269-299.

Korobkov, A. V., and Z. A. Zaionchkovskaia

2004 "The Changes in the Migration Patterns in the Post-Soviet States: The First Decade." Communist and Post-Communist Studies 37(4):481-508.

Kulu, H., and T. Tammaru

2000 "Ethnic Return Migration from the East and the West: The Case of Estonia in the 1990s." Europe-Asia Studies 52(2):349-369.

Kumskov, G. V.

2002 Patterns and Peculiarities of Contemporary Migration Processes in Kyrgyzstan. Bishkek: Kyrgyz-Russian Slavic University (in Russian).

, et al.

1997 Socioeconomic Problems of Population Migration in the Kyrgyz Republic (1991-1996). Bishkek: Kyrgyz-Russian Slavic University (in Russian). 
Laruelle, $M$.

2006 "Le Nouveau Rôle de la Russie en Asie Centrale: Les Migrations de Travail des Centreasiatiques vers la Fédération Russe." La Revue Internationale e Stratégique 64:133-142.

Lewis, E. G.

1971 "Migration and Language in the USSR." International Migration Review 5(2):147-179.

Lindstrom, D. P., and S. G. Saucedo

2002 "The Short- and Long-Term Effects of U.S. Migration Experience on Mexican Women's Fertility." Social Forces 80(4):1341-1368.

Mansoor, A., and B. Quillin

2006 Migration and Remittances: Eastern Europe and the Former Soviet Union. Washington, DC: The World Bank.

Massey, D. S.

1990 "Social Structure, Household Strategies and the Cumulative Causation of Migration." Population Index 56(1):3-26.

Menjívar, C.

2000 Fragmented Ties: Salvadoran Immigrant Networks in America. Berkeley: University of California Press.

Nikolaev, S.

1994 "Russians in Uzbekistan." In The New Russian Diaspora: Russian Minorities in the Former Soviet Republics. Ed. V. Shlapentokh, M. Sendich, and E. Payin. New York, NY: M.E. Sharpe. Pp. 107-122.

Radnitz, S.

2006a "Weighing the Political and Economic Motivations for Migration in Post-Soviet Space: The Case of Uzbekistan." Europe-Asia Studies 58(5):653-677.

2006b "What Really Happened in Kyrgyzstan?” Journal of Democracy 17(2):132-146.

Root, B. D., and G. F. De Jong

1991 "Family Migration in a Developing Country." Population Studies 45(2):221-233.

Rowland, R. H.

2001 "Regional Population Change in Kazakhstan during the 1990s and the Impact of Nationality Population Patterns: Results from the Recent Census of Kazakhstan.” Post-Soviet Geography and Economics 42(8):571-614.

1990 “Economic Region Net Migration Patterns in the U.S.S.R.: 1979-1989.” Soviet Geography 31(9):657-678.

1988 "Union Republic Migration Trends in the USSR during the 1980s." Soviet Geography 29(9):809-829.

[The] Russian Federation

2006a "On Establishing an Acceptable Share of Foreign Workers Employed by Establishments Operating in Retail Trade on the Territory of the Russian Federation in 2007." Regulation of the Government of the Russian Federation, Regulation \#683, November 15 (in Russian).

2006b "On Measures Aimed at Assisting Voluntary Resettlement in Russia of Compatriots Residing Abroad." Decree of the President of the Russian Federation, Decree \# 637, 22 June (in Russian). 
Schiller, N. G., L. Basch, and C. S. Blanc

1995 "From Immigrant to Transmigrant: Theorizing Transnational Migration." Anthropological Quarterly 68(1):48-63.

Shuller, M., and Z. Kudabayev

2004 "Migration of Kyrgyzstan's Population." In The Population of Kyrgyzstan. Ed. Z. Kudabayev, M. Guillot, and M. Denisenko. Bishkek: National Statistical Committee of the Kyrgyz Republic. Pp. 281-302 (in Russian).

Stinner, W. F., and M. Van Loon

1992 "Community Size Preference Status, Community Satisfaction and Migration Intentions." Population and Environment 14(2):177-195.

Subbotina, I. A.

1997 "Russians in Kazakhstan: The Migration Situation on the Eve and After the Breakup of the USSR." In Russians in the New Abroad: The Migration Situation, Relocation, and Adaptation in Russia. Ed. S. S. Savoskul. Moscow: Institute of Ethnology of the Russian Academy of Sciences. Pp. 154-175 (in Russian).

Tishkov, V. A.

1997 "The Russians Are Leaving: Central Asia and Kazakhstan." In Ethnicity, Nationalism and Conflict In and After the Soviet Union: The Mind Aflame. London and Thousand Oaks, CA: Sage Publications. Pp. 115-134.

1994 "Russians in Central Asia." In Russians in Near Abroad. Ed. V. I. Kozlov and E. A. Shervoud. Moscow: Institute of Ethnology and Anthropology of the Russian Academy of Sciences. Pp. 140-153 (in Russian).

, Z. Zayonchkovskaya, and G. Vitkovskaya

2005 "Migration in the Countries of the Former Soviet Union." Global Commission on International Migration. <http://www.gcim.org>.

Uehling, G.

2002 "Sitting on Suitcases: Ambivalence and Ambiguity in the Migration Intentions of Crimean Tatar Women." Journal of Refugee Studies 15(4):88-408.

Vitkovskaya, G., ed.

1999 "Potential Migration of Russian-Speaking Populations from Central Asia to Russia." In Population under Duress: The Geodemography of Post-Soviet Russia. Ed. G. J. Demko, G. Ioffe, and Z. Zayonchkovskaya. Boulder, CO: Westview Press. Pp. 149-176.

[The] World Bank

2007 "Country Profiles: Kyrgyzstan.” <http://www.worldbank.org.>.

Yang, $\mathrm{X}$.

2000 "Determinants of Migration Intentions in Hubei Province, China: Individual versus Family Migration." Environment and Planning A. 32(5):769-787.

Zayonchkovskaya, Z.

2000 "Recent Migration Trends in the Commonwealth of Independent States." International Social Science Journal 52(165):343-355.

Zlotnik, H.

1995 “The South-North Migration of Women." International Migration Review 29(1):229_ 254. 